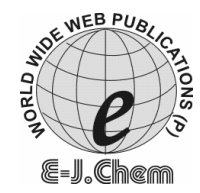

http://www.e-journals.net

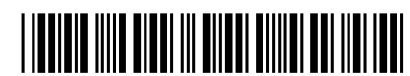

ISSN: 0973-4945; CODEN ECJHAO

E-Journal of Chemistry

2009, 6(2), 466-468

\title{
Studies on Insecticidal Activity of Some Hydroxytriazene Derivatives
}

\author{
S. KUMAR, MEENAKSHI GARG, J. S. JODHA, R. P. SINGH, \\ NEELAM PAREEK, R. S. CHAUHAN and A. K. GOSWAMI*' \\ *Department of Chemistry, \\ M.L. Sukhadia University, Udaipur-313001, (Raj.), India. \\ akumargoswami@rediffmail.com
}

Received 23 September 2008; Accepted 10 November 2008

\begin{abstract}
Nine hydroxytriazenes have been synthesized and screened for their insecticidal activity against one day old Drosophila melanogaster Meig (Fruit fly). Out of all the nine compounds screened, 3-hydroxy-3- $n$-propyl-1- $m$ chlorophenyltriazene is the most active having $\mathrm{LC}_{50}$ values $0.9847 \mathrm{ppm}$. The least active compound is 3-hydroxy -3- $n$-propyl-1-p-methylphenyltriazene, whose values are $16.52 \mathrm{ppm}$. In general, the $\mathrm{LC}_{50}$ values range from 3.92 to $5.52 \mathrm{ppm}$.
\end{abstract}

Keywords: Hydroxytriazenes, Insecticidal activity, Drosophila melanogaster Meig.

\section{Introduction}

Hdroxytriazenes have been extensively used as analytical reagents ${ }^{1-2}$. Recently, they have also been screened for their biological activity including insecticidal activity in our laboratories $^{3-8}$. In the present investigation, nine hydroxytriazenes have been synthesized and screened for their insecticidal activity against one day old males of fruit fly (Drosophila melanogaster Meig).

\section{Experimental}

\section{Synthesis of hydroxytriazenes}

All the nine hydroxytriazenes have been synthesized by the method as reported in the literature ${ }^{9-14}$. The method involves preparation of aryl or alkyl hydroxylamine, aryldiazonium salts and coupling them at the temperature between $0-5^{\circ} \mathrm{C}$. The compounds so prepared were crystallized and their compositions were verified by elemental analysis, melting point determinations and I.R. studies.

\section{Details of culture}

In wide mouth bottles at a temperature of $27 \pm 1{ }^{0} \mathrm{C}$ Drosophila melanogaster Meig were reared on the agar medium described by Lewis ${ }^{15}$. For preparing the medium, maize flour 
(150 g), jaggary (130 g), agar-agar (20 g), yeast (22 g), distilled water (1500 $\mathrm{mL})$ and propionic acid $(1 \mathrm{~mL})$ were mixed and heated for 10 to $15 \mathrm{~min}$. The flasks were allowed to cool. In each flask about 10-20 insects of D. melanogaster were released and it was covered immediately by muslin cloth. The newly emerged one day old male flies were used for investigation.

\section{Toxicity studies}

Micro bioassay was done using one day old male Drosophila melanogaster Meig by residue film method ${ }^{16}$.

\section{Preparation of stock solution}

A stock solution of $1000 \mathrm{ppm}$ of each hydroxytriazenes was prepared in ethanol and acetone. Solutions of lower concentration were prepared by proper dilution of stock solution with the solvent.

\section{Procedure}

Residue film of one $\mathrm{mL}$ of the solution of each hydroxytriazene was prepared on Petri dish (10 cm diameter) by spreading $0.5 \mathrm{~mL}$ of the solution on each of the two parts of the Petri dish. The solution in both the parts of Petri dish was swirled gently in order to coat the entire surface. Thereafter, 20 one day old male insects were released in Petri dish and exposed for $24 \mathrm{~h}$. The insects were anaesthetized by keeping them in deep freeze for about three minutes in order to make them inactive for about one minute. Each such treatment was replicated thrice. To record the natural mortality a control in three replication was also run by side. The mortality was taken after $24 \mathrm{~h}$ moribund insects were also counted as dead.

\section{Results and Discussion}

For the estimation of $\mathrm{LC}_{50}$ values a method of probit analysis has been applied which involves changing of observed percent mortality to corrected percent mortality. For sake of brevity all the table and data of regression equation have not been incorporated. The concentration range used for test compound was $100 \mathrm{ppm}$ and $500 \mathrm{ppm}$ depending up on the response in individual concentration. Table 1 show $\mathrm{LC}_{50}$ values and relative toxicity of hydroxytriazenes against one day old male $D$. melanogaster Meig

Table 1. $\mathrm{LC}_{50}$ values and relative toxicity of hydroxytriazenes against $D$. melanogaster Meig.

\begin{tabular}{clc}
\hline S.No. & \multicolumn{1}{c}{ Name } & $\begin{array}{c}\mathrm{LC}_{50} \text { for } \\
\mathrm{HT}^{*} \mathrm{ppm}\end{array}$ \\
\hline 1 & 3-Hydroxy-3- $m$-sulphonato(sodium salt)phenyl-1-o-nitrophenyltriazene & 5.52 \\
2 & 3-Hydroxy-3-phenyl-1- $o$-chlrophenyltriazene & 14.09 \\
3 & 3-Hydroxy-3- $p$-tolyl-1- $p$-sulphonato(sodium salt)phenyltriazene & 3.92 \\
4 & 3-Hydroxy-3- $n$-proply-1- $m$-chlorophenytrianzene & 0.98 \\
5 & 3-Hydroxy-3- $n$-propyl-1- $p$-methylphenyltriazene & 16.52 \\
6 & 3- Hydroxy-3-m-sulphonato(sodium salt)-1- $o$-chlorophenyltriazene & 13.46 \\
7 & 3- Hydroxy-3-ethyl-1-(4- sulponamidophenyl )triazene & 15.77 \\
8 & 3- Hydroxy-3-methyl-1-m-nitrophenyltriazene & 4.13 \\
9 & 3- Hydroxy-3- $p$-tolyl-1- $p$-nitrophenyltriazene & 15.70 \\
\hline
\end{tabular}

*Hydroxytriazenes

Perusal of Table 1 reveals that out of the nine compound screened, compound number 4 is the most active compound and its $\mathrm{LC}_{50}$ value is $0.98 \mathrm{ppm}$ whereas compound number 5 is 
the least active having value $16.52 \mathrm{ppm}$. Most of the other compounds have $\mathrm{LC}_{50}$ values in the range of 3.92 to $15.77 \mathrm{ppm}$, which is fairly good and indicates possibility of studying these compounds further.

In the residual film method the probable mechanism of action of hydroxytriazenes might be as contact poison. Slight activity may be due to vaporization of the compounds in the closed Petri dish.

The contact poison either directly penetrates through body integument or may cause oxidation suffocating the insects. Thus it is certain that hydroxytriazene can be useful as insecticidal compounds if explored further.

\section{References}

1. Gorji Deepika K, Chauhan R S, Goswami A K and Purohit D N, Rev Anal Chem., 1998, 17(4), 223-233.

2. Kumar S, Goswami A K and Purohit D N, Rev Anal Chem., 2003, 22(1), 73-80.

3. Rezaei B, Ressalan S, Chauhan R S, Goswami A K and Purohit D N, Asian J Chem., 1997, 9(4), 891-892.

4. Ombaca O, Ressalan S, Chauhan R S, Goswami A K and Purohit D N, Insecticidal activities of hydroxytriazene: A new class of potential insecticides. Pestology., 1980, XXII (8), 9-10.

5. Ombaca O, Ressalan S, chauhan R S, Goswami A K and Purohit D N, Pesticide Research J., 1998, 10(2), 235-236.

6. Goswami A K and Purohit D N, Analytical Sciences (Japan), 2001, i789-791.

7. Goswami A K, Pesticide Research J., 2002, 14(2), 213-215.

8. Hura I S, Naulankha Neelam, Goswami A K and Shrivastav M K, Indian J Microbiol., 2003, 43, 275-276.

9. Bamberger E, Ber., 1896, 29,104.

10. Bamberger E and Renauld E, Ber., 1887, 30, 2280.

11. Bamberger E and Tshirner F, Ber., 1899, B, 1677.

12. Bamberger E and Busdrof W, Ber., 1990, 33, 3510.

13. Elkins M and Hunter L, J Chem Soc., (London) 1938, 1346.

14. Sogani N C and Bhattacharya S C, Anal Chem., 1956, 28, 81; J Indian Chem Soc., 1956, 36, 563.

15. Lewis EB, Department of Biology, University of Dergen, Drosophila Information 1960, 34, 117.

16. Gupta HCL, Microbioassay of residue of insecticides in/on onion, M. Sc.,(Agr) Thesis, University of Udaipur, 1968. 


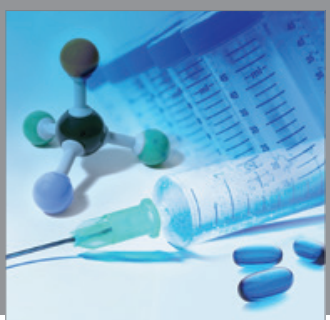

International Journal of

Medicinal Chemistry

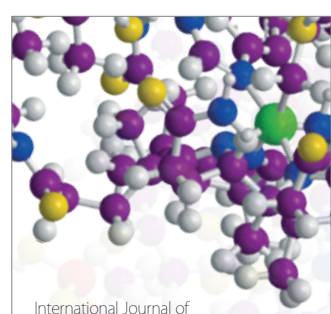

Carbohydrate Chemistry

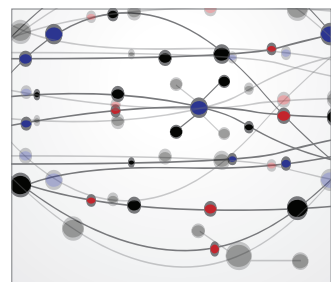

The Scientific World Journal
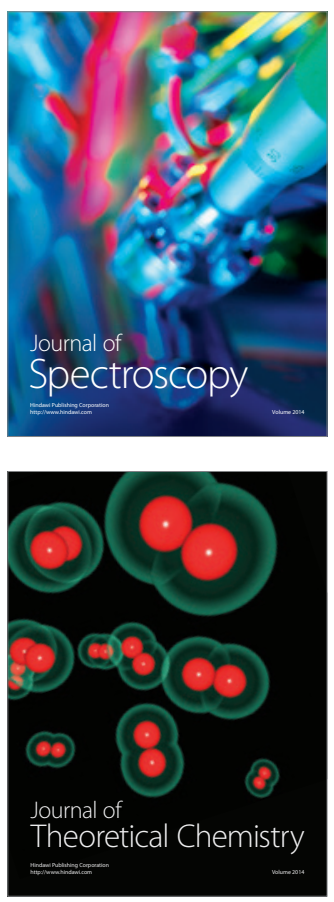
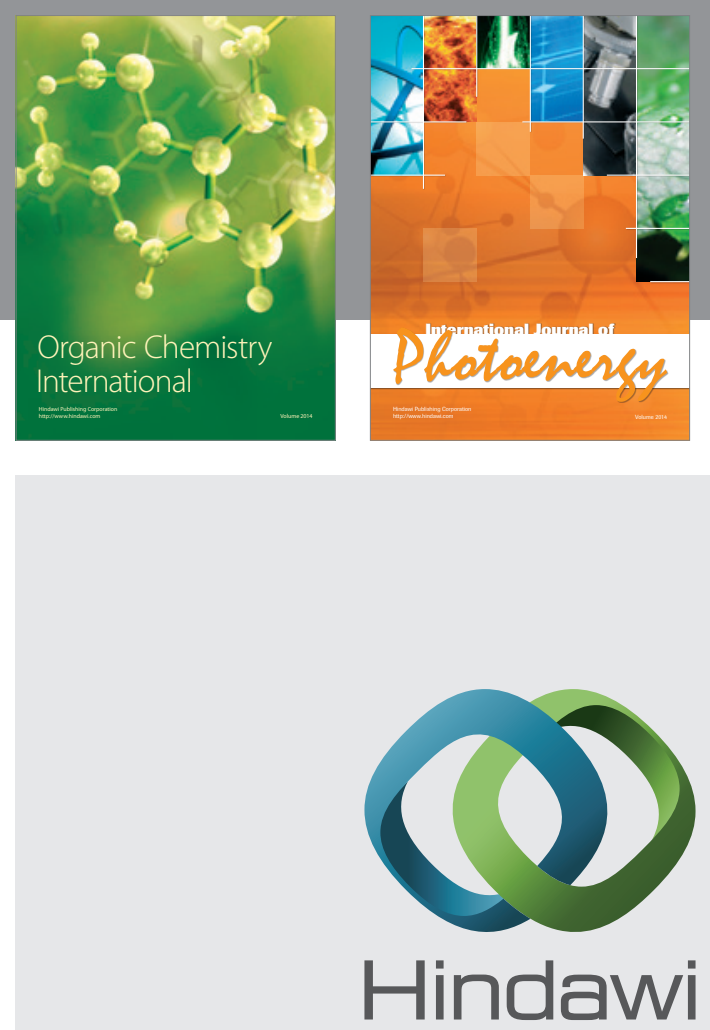

Submit your manuscripts at

http://www.hindawi.com
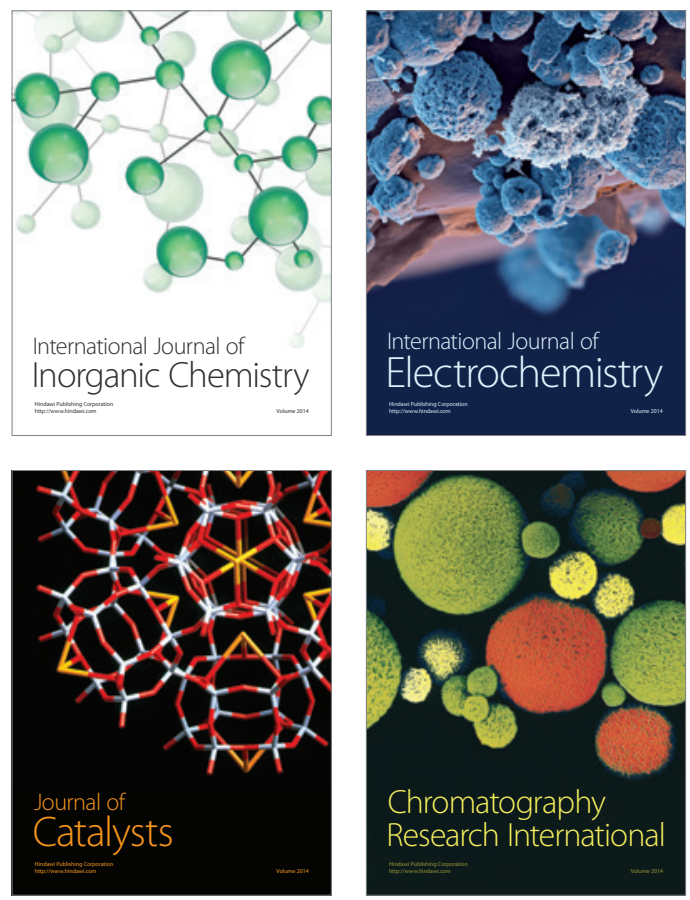
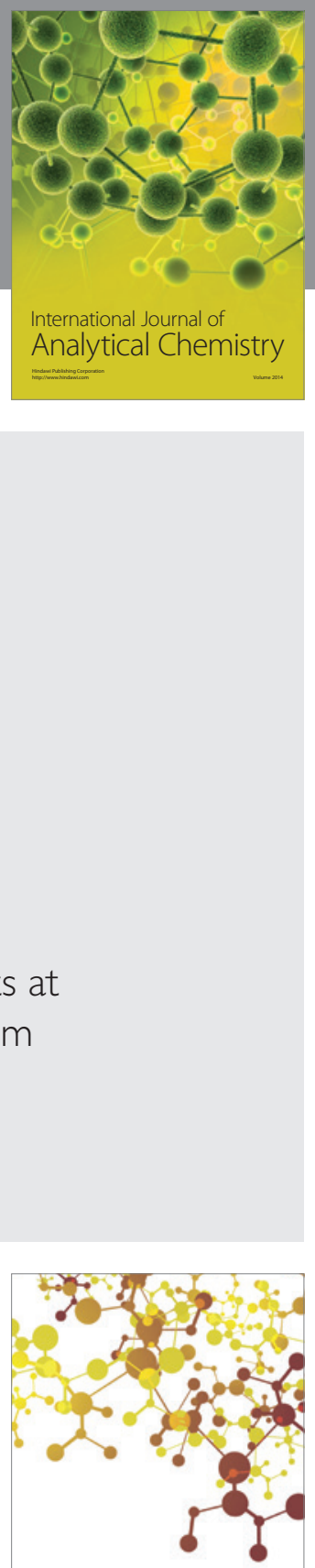

Journal of

Applied Chemistry
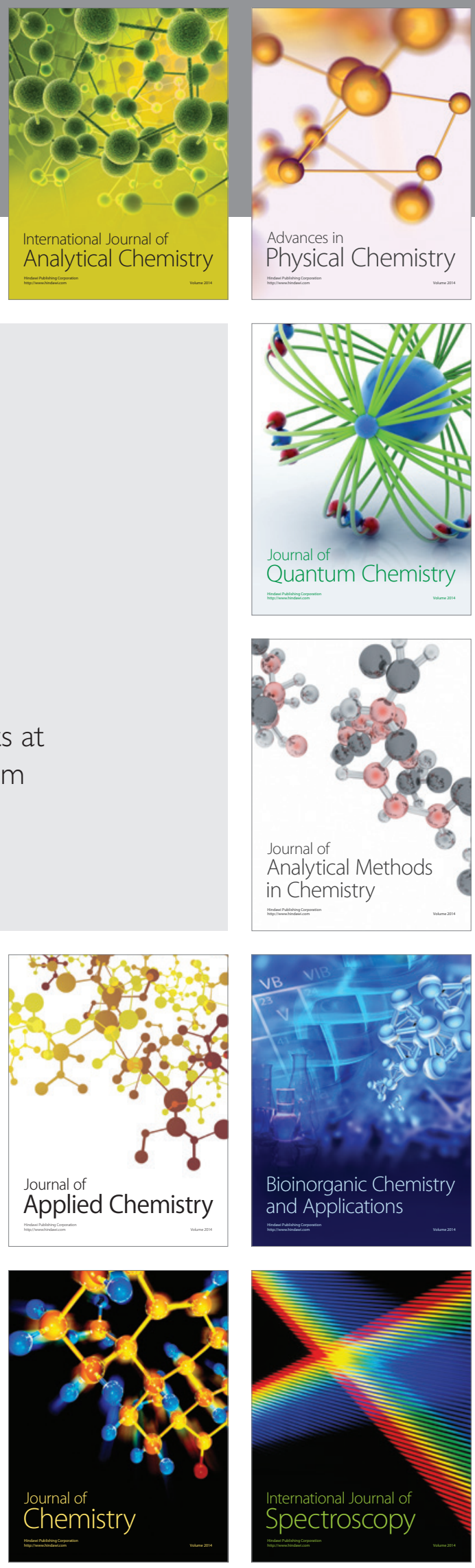